\title{
The antianxiety activity of aqueous extract of Withania coagulans fruits in swiss albino mice by elevated plus maze
}

\author{
Devesh D. Gosavi ${ }^{1}$, Amit S. Kamdi²*, Suvarna M. Kalambe², Pankaj N. Bohra ${ }^{3}$
}

${ }^{1}$ Department of Pharmacology, Mahatma Gandhi Institute of Medical Sciences, Sewagram, Maharashtra, India ${ }^{2}$ Department of Research and Development, Sanjeevani Multipurpose Society, Mul, Maharashtra, India

${ }^{3}$ Department of Paediatrics, SNEH Foundation, Chichwad, Pune, Maharashtra, India

Received: 11 June 2020

Revised: 12 July 2020

Accepted: 13 July 2020

*Correspondence:

Dr. Amit S. Kamdi,

Email: dramitkamdi99@gmail.com

Copyright: ( $)$ the author(s), publisher and licensee Medip Academy. This is an open-access article distributed under the terms of the Creative Commons Attribution Non-Commercial License, which permits unrestricted non-commercial use, distribution, and reproduction in any medium, provided the original work is properly cited.

\begin{abstract}
Background: Several anti-anxiety drugs used today have the numerous side effects. The Withania coagulans a rare species, is not studied much for its actions on anxiety except in late seventies where it was explored for neuropsychopharmacology. Thus, it was thought commendable to explore the anti-anxiety activities of aqueous extract of Withania coagulans fruits in swiss albino mice using elevated plus maze test.

Methods: Elevated plus maze (EPM) test was used for evaluating the anti-anxiety action of Withania coagulans fruits' aqueous extract. If the extract had anti-anxiety action, then it was expected that the time spent in the open space would increase and that in the closed space would decrease. This increase in time in the open space, if found statistically significant, was considered for antianxiety action.

Results: There was statistically highly significant ( $p$ value $<0.001$ ) association observed between the aqueous extract of Withania coagulans fruits with antianxiety action in the swiss albino mice by elevated plus maze test.

Conclusions: The aqueous extract of Withania coagulans fruits did prove the antianxiety effect in the swiss albino mice by elevated plus maze test.
\end{abstract}

Keywords: Anti-anxiety, Swiss albino mice, Withania coagulans, Elevated plus maze

\section{INTRODUCTION}

In general anxiety and fear are emotional responses to environmental stimuli, usually inherent as a reflex in human behavior to avoid a threatening or unpleasant situation. It is therefore a basic instinct and causes the body to react in a certain way to avoid the threat or flee. ${ }^{1}$ Prevalence of Mental health disorder is about 60 per thousand in India. ${ }^{2}$ Prevalence of anxiety disorder in Elderly is $9 \%$ according to ICD-9 of World Health Organization. ${ }^{3,4}$ Yet, the prevalence of anxiety disorders in in India is $3.6 \% .^{5}$ Currently used drugs for anxiolytic action are benzodiazepines (BZD), azapirones, selective serotonin reuptake inhibitor (SSRI) and antiepileptics. However, benzodiazepines cause sedation, azapirones take 2 weeks for their action to develop and usually 2-3 weeks of continuous treatment with SSRIs are required for a clinical effect to appear. ${ }^{6}$ Antiepileptic drugs have other serious side effects.

Withania coagulans is a rare species. The plant is mainly used for the milk coagulation. ${ }^{7}$ The water, soaked overnight with fruits, drunk by diabetic patients for about a month is a very nice remedy to control blood sugar levels. ${ }^{7}$ It is not commonly found and therefore it is categorized as 'Vulnerable species'. 8 As a result, not much work is done on this plant to see the effect on central nervous system (CNS). In 1977 Budhiraja et al reported CNS depressant activity of this plant. ${ }^{9}$ Thereafter this plant was not much explored for the CNS 
activity, though lot of work was done on diabetes and other diseases. ${ }^{10-13}$ Therefore, it was thought worthwhile to investigate neuropsychopharmacology parameter like anti-anxiety activity of Withania coagulans fruits aqueous extract using elevated plus maze (EPM). Mice have an aversion for high and open space and prefer enclosed space, thus spend more time in the enclosed arm. ${ }^{14}$ The fall in time spent in open arms as well as less number of open arm entries are the indicators of high level of fear or anxiety. On the other hand, drugs having antianxiety activity raise time spent in open arm and number of open arm entries. ${ }^{15,16}$

\section{METHODS}

\section{Animals}

Healthy male swiss albino mice weighing between 20-35 grams were chosen for anti-anxiety activity. The mice were procured after taking permission from Institutional Animal Ethical Committee (IAEC) of MGIMS. The animals were housed in polyvinyl wire web enclosures in the central animal room of institute approved by CPCSEA. The animals were divided into 5 groups of 6 mice each. The rodents were kept under customary laboratory condition (12 hour light and dark cycle with light on at 6 am and off at $6 \mathrm{pm}$ ) and temperature $\left(22^{\circ} \mathrm{C} \pm 3^{\circ} \mathrm{C}\right)$, humidity $(60 \pm 10 \%)$ with free access to food and water ad libitum according to OECD's revised draft guidelines 425 and the committee for the purpose of control and supervision of experiments on animals (CPCSEA), ministry of social justice and empowerment, government of India. ${ }^{17}$ The animals were allowed to adapt to the new surrounding by giving rest of one week before subjecting them to experimentation. All the experimental mice were transferred to the behavior testing room $30 \mathrm{~min}$ prior to beginning the trial to accustom with the environment of the behavior testing room. Test was performed between 9:00 am and 6:00 pm. Health of each animal monitored daily. Each mouse was tested once.

\section{Collection of plant material}

Since the Withania coagulans is a rare plant, and it is grown in the arid area of India, we purchased the whole plant from the market. The whole plant was authenticated by the Botanist. Thereafter the dried fruits were purchased from the market in bulk.

\section{Preparation of extract}

The fruits (with persistent calyx and pedicle) of Withania coagulans were dried in shade for 15 days in closed room at room temperature, powdered in an electric mixture, sieved and stored in an airtight container for study. First the powder was tried for its solubility both in distilled water and ethanol and it was found that it had limited solubility. Thereafter the decision was taken to get the extract by Soxhlet procedure. Thus, the aqueous extract of the Withania coagulans fruits were prepared by using Soxhlet apparatus. The extract dissolved in suitable vehicle was given orally.

\section{Soxhlet aqueous extraction ${ }^{18}$}

The $30 \mathrm{~g}$ of powder material was charged inside the thimble of the primary chamber of the Soxhlet extractor. The Soxhlet extractor was positioned onto a flask comprising the extraction liquid (100\% distilled water). Thereafter a condenser (having continuous flow of tap water through inlet and outlet to condense the vapors) was attached to the top of the primary chamber. The solvent was heated to evaporate. The solvent vapors passed up through the distillation arm. The vapors were condensed, liquefied and the warm liquid was collected inside the chamber housing the thimble of powder. The certain amount of the desired dissolved in the warm solvent. When the Soxhlet chamber was almost full, it was automatically emptied by a siphon tube with the solvent passing back down to the flask. This cycle was allowed to repeat many times over hours to days. During each cycle, a part of the non-volatile compound dissolved in the water. After many cycles the desired compound was concentrated in the distillation flask. The appearance of colorless solvent in the siphon tube was the indication of exhaustive extraction and based on that, further extraction was terminated. The non-soluble part of the extracted solid left in the thimble was discarded. The extract was again dried in the dark and closed room at room temperature. The percentage of yield was $7 \%$ after drying. Thus, we used $30 \mathrm{~g}$ of crude powder but we got 2 $\mathrm{g}$ of extract.

\section{Preparation of drug formulation}

The fresh solution was prepared by dissolving the extract in distilled water before each experiment for oral administration.

\section{Pilot study}

A pilot study was done using the various doses of the test drugs i.e. $62.5 \mathrm{mg} / \mathrm{kg}, 100 \mathrm{mg} / \mathrm{kg}, 125 \mathrm{mg} / \mathrm{kg}, 200 \mathrm{mg} / \mathrm{kg}$, $250 \mathrm{mg} / \mathrm{kg}, 500 \mathrm{mg} / \mathrm{kg}$ and $1000 \mathrm{mg} / \mathrm{kg}$. The doses 200 $\mathrm{mg} / \mathrm{kg}, 500 \mathrm{mg} / \mathrm{kg}$ and $1000 \mathrm{mg} / \mathrm{kg}$ were selected as working doses for all the experiments in present study.

\section{Control, standard and test drugs}

Distilled water was given as vehicle for control. Diazepam was used as the standard drug. The animals were treated 30 minutes before the experiment with the test drugs (WCF AqE of $200 \mathrm{mg} / \mathrm{kg}, 500 \mathrm{mg} / \mathrm{kg}$ and 1000 $\mathrm{mg} / \mathrm{kg}$ doses p.o.). However, the test drug was given every day for 30 days throughout the period of experiment. The mice were observed for $5 \mathrm{~min}$. Recordings were done on day 1 , day 8 , day 15 , day 23 and day 30 for all the groups. The recordings were taken half an hour after drug administration to the respective 
group. After each trial the equipment was cleaned with super hypochlorous water to prevent the bias based on olfactory cues.

Drugs were given in the following manner.

Control: Vehicle (distilled water) $2 \mathrm{ml} / \mathrm{kg}$ p.o. once a day for 30 days.

Standard: Standard drug (diazepam) $5 \mathrm{mg} / \mathrm{kg}$ i.p. once half an hour before test.

AQ-200: WCF AqE $200 \mathrm{mg} / \mathrm{kg}$ p.o. once a day for 30 days.

AQ-500: WCF AqE $500 \mathrm{mg} / \mathrm{kg}$ p.o. once a day for 30 days.

AQ-1000: WCF AqE $1000 \mathrm{mg} / \mathrm{kg}$ p.o. once a day for 30 days.

Where, WCF AqE = Withania coagulans fruits aqueous extract.

\section{Elevated plus maze apparatus}

The EPM consisted of two open arms crossed with two closed arms making a sign of plus. The arms were connected together to form a central square. Maze made of powder coated mild steel and plexiglass. Open chamber was $30 \mathrm{~cm}$ in length and $8 \mathrm{~cm}$ in breadth. Enclosed chamber had opaque plexiglass walls of $15 \mathrm{~cm}$ height. The 16 characters, 2 lines display, showed the time elapsed, time in closed and open arms separately. The 9 pairs of infrared beams sensed animal movement. Variable timer for experiment duration from 1-99 minutes was available from the front panel and it was set at 5 minutes duration.

There was the separate control unit for minimizing human intervention. The apparatus was elevated to the height of $25 \mathrm{~cm}$ in a dimly illuminated room.

\section{Elevated plus maze procedure ${ }^{19}$}

The mice were placed individually in the central square of the EPM with the head directed towards close arm and observed for the next 5 minutes. The evaluation was done for the time spent in the close arm, time spent in the open arm and number of entries into the open arm for five minutes. It was observed that animals spent more time in open arm as compared to closed arm if the particular drug has antianxiety activity. Number of entries into the open arm will be increased in the test group if the test drug has antianxiety activity as compared to control. An entry is defined as the presence of all four paws in the respective arm. After each trial the equipment was cleaned with super hypochlorous water to prevent the bias based on olfactory cues.

\section{RESULTS}

As illustrated in the Table 1 , on day 1 and day 8 there was no statistically significant difference in all the parameters like time spent in the open arm (open), time spent in the closed arm (close) and entries into open arm (EOA) for all the three doses of $200 \mathrm{mg} / \mathrm{kg}, 500 \mathrm{mg} / \mathrm{kg}$ and $1000 \mathrm{mg} / \mathrm{kg}$ of WCF AqE compared to control. However, on day 15, day 23 and day 30 there were statistically significant differences in all the parameters like open, close and EOA for all the three doses of 200 $\mathrm{mg} / \mathrm{kg}, 500 \mathrm{mg} / \mathrm{kg}$ and $1000 \mathrm{mg} / \mathrm{kg}$ of $\mathrm{WCF} \mathrm{AqE}$ compared to control.

Table 1: Effect of oral administration of WCF AqE on time spent (mean \pm SD) in open arm (in seconds), closed arm (in seconds) and entries into open arm in elevated plus maze test.

\begin{tabular}{|c|c|c|c|c|c|c|}
\hline Variable & & Control & Standard & AQ-200 & AQ-500 & AQ-1000 \\
\hline \multirow{3}{*}{ Day 1} & Open & $55.16 \pm 18.34$ & $60.83 \pm 22.78$ & $51.83 \pm 27.96$ & $61.83 \pm 31.64$ & $56.33 \pm 40.12$ \\
\hline & Close & $213.83 \pm 11.95$ & $207 \pm 21.50$ & $203.16 \pm 17.29$ & $211 \pm 17.09$ & $204.16 \pm 24.79$ \\
\hline & EOA & $2.50 \pm 2.16$ & $2.16 \pm 1.72$ & $2.33 \pm 1.86$ & $2.66 \pm 1.75$ & $2.83 \pm 1.47$ \\
\hline \multirow{3}{*}{ Day 8} & Open & $41 \pm 17.22$ & $53.16 \pm 8.23$ & $30.33 \pm 18.22$ & $36.16 \pm 7.25$ & $38.50 \pm 27.60$ \\
\hline & Close & $223.16 \pm 31.26$ & $202.83 \pm 19.56$ & $221.83 \pm 20.94$ & $231.83 \pm 20.94$ & $220 \pm 28.34$ \\
\hline & EOA & $2.83 \pm 1.94$ & $2.50 \pm 2.07$ & $2.16 \pm 1.83$ & $2.33 \pm 0.81$ & $2.50 \pm 0.83$ \\
\hline \multirow{3}{*}{ Day 15} & Open & $24.66 \pm 7.60$ & $66.66 \pm 17.64 * * *$ & $68.66 \pm 15.53 * * *$ & $79.66 \pm 17.07 * * *$ & $92 \pm 15.91 * * *$ \\
\hline & Close & $248.83 \pm 13.36$ & $153.66 \pm 12.97 * * *$ & $177.33 \pm 16.42 * * *$ & $169 \pm 14.76^{* * *}$ & $142.16 \pm 19.97 * * *$ \\
\hline & EOA & $2.00 \pm 1.26$ & $4.50 \pm 0.54 * * *$ & $5.33 \pm 0.51 * * *$ & $6.16 \pm 1.47 * * *$ & $6.50 \pm 1.22 * * *$ \\
\hline \multirow{3}{*}{ Day 23} & Open & $21.50 \pm 10.91$ & $97.66 \pm 23.20 * * *$ & $113.50 \pm 14.32 * * *$ & $131.83 \pm 30.36 * * *$ & $155 \pm 18.76 * * *$ \\
\hline & Close & $250.83 \pm 18.86$ & $143 \pm 32.98 * * *$ & $131.16 \pm 26.94 * * *$ & $116 \pm 15.82 * * *$ & $99.83 \pm 19.13 * * *$ \\
\hline & EOA & $2.16 \pm 0.75$ & $5.50 \pm 1.04 * * *$ & $6.33 \pm 1.36 * * *$ & $7.16 \pm 1.16^{* * *}$ & $7.83 \pm 1.16^{* * *}$ \\
\hline \multirow{3}{*}{ Day 30} & Open & $17 \pm 10.13$ & $148.16 \pm 37.13$ *** & $162.16 \pm 29.94 * * *$ & $179.16 \pm 24.70 * * *$ & $206 \pm 54.61 * * *$ \\
\hline & Close & $250.83 \pm 23.14$ & $101.66 \pm 22.76 * * *$ & $94.50 \pm 44.97 * * *$ & $70 \pm 22.53 * * *$ & $50.83 \pm 20.44 * * *$ \\
\hline & EOA & $2.50 \pm 0.83$ & $7.16 \pm 1.32 * * *$ & $7.50 \pm 1.04 * * *$ & $8 \pm 0.89 * * *$ & $8.83 \pm 0.75 * * *$ \\
\hline
\end{tabular}

$* \mathrm{p}<0.05, * * \mathrm{p}<0.01$ and $* * * \mathrm{p}<0.001$ when compared to control group; $\mathrm{n}=6$ in each group. 
WCF AqE: Withania coagulans fruits aqueous extract.

Open: Time spent in open arm (in seconds).

Close: Time spent in closed arm (in seconds).

EOA: Entries into open arm.

Control: Vehicle (distilled water) $2 \mathrm{ml} / \mathrm{kg}$ p.o. once a day for 30 days.

Standard: Standard drug (diazepam) $5 \mathrm{mg} / \mathrm{kg}$ i.p. half an hour before test.

AQ-200: WCF AqE $200 \mathrm{mg} / \mathrm{kg}$ body weight p.o. once a day for 30 days.

AQ-500: WCF AqE $500 \mathrm{mg} / \mathrm{kg}$ body weight p.o. once a day for 30 days.

AQ-1000: WCF AqE $1000 \mathrm{mg} / \mathrm{kg}$ body weight p.o. once a day for 30 days.

\section{Activity in the open arm}

Further clarified from the Figure 1, time spent in the open arm increased significantly $(\mathrm{p}<0.001)$ for all the three doses of WCF AqE on days 15, 23 and 30 compared to control on those days. This increase was comparable with that of standard diazepam. Furthermore, the dose response relationship was observed with WCF AqE for this parameter.

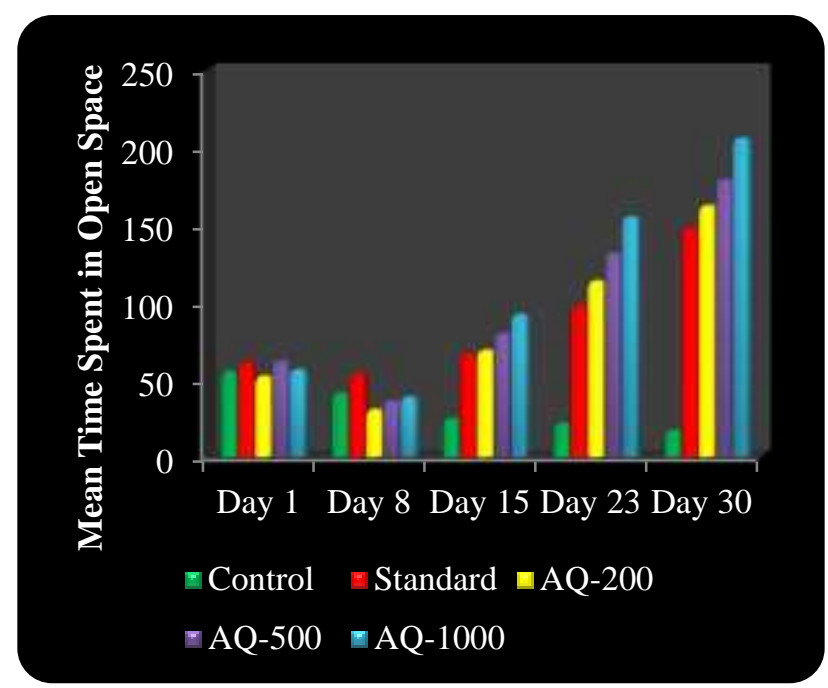

Figure 1: Effect of oral administration of WCF AqE on time spent in the open arm (in seconds) in the elevated plus maze test ( $n=6$ in each group).

WCF AqE: Withania coagulans fruits aqueous extract.

Control: Vehicle (distilled water) $2 \mathrm{ml} / \mathrm{kg}$ p.o. once a day for 30 days.
Standard: Standard drug (diazepam) $5 \mathrm{mg} / \mathrm{kg}$ i.p. half an hour before test.

AQ-200: WCF AqE $200 \mathrm{mg} / \mathrm{kg}$ body weight p.o. once a day for 30 days.

AQ-500: WCF AqE $500 \mathrm{mg} / \mathrm{kg}$ body weight p.o. once a day for 30 days.

AQ-1000: WCF AqE $1000 \mathrm{mg} / \mathrm{kg}$ body weight p.o. once a day for 30 days.

\section{Activity in the closed arm}

Additionally, explained from the Figure 2, time spent in the closed arm decreased significantly $(p<0.001)$ for all the three doses of WCF AqE on days 15, 23 and 30 compared to control on those days. This decrease was comparable with that of standard diazepam. Moreover, the dose response relationship was observed with WCF $\mathrm{AqE}$ for this parameter.

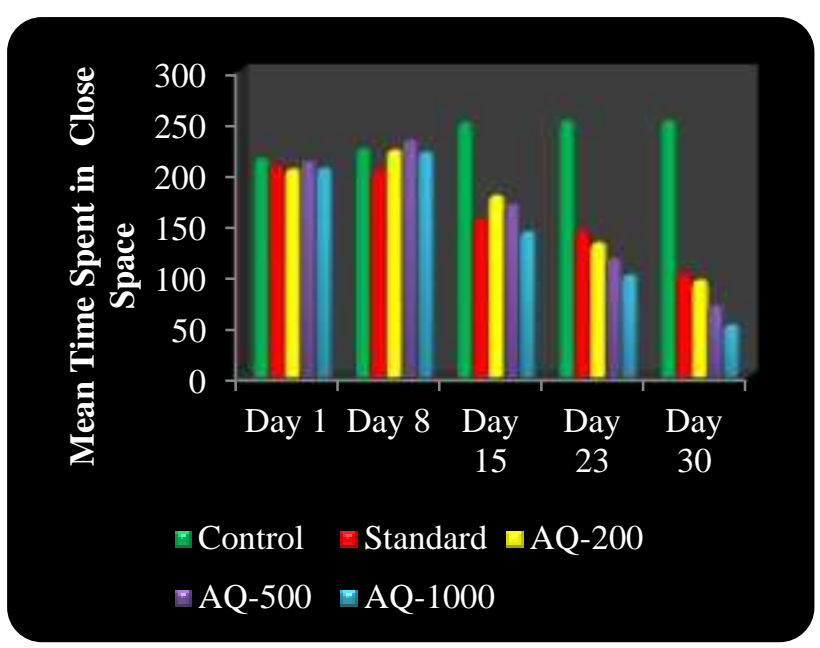

Figure 2: Effect of oral administration of WCF AqE on time spent in the close arm (in seconds) in the elevated plus maze test ( $n=6$ in each group).

WCF AqE: Withania coagulans fruits aqueous extract.

Control: Vehicle (distilled water) $2 \mathrm{ml} / \mathrm{kg}$ p.o. once a day for 30 days.

Standard: Standard drug (diazepam) $5 \mathrm{mg} / \mathrm{kg}$ i.p. half an hour before test.

$A Q$-200: WCF AqE $200 \mathrm{mg} / \mathrm{kg}$ body weight p.o. once a day for 30 days.

AQ-500: WCF AqE $500 \mathrm{mg} / \mathrm{kg}$ body weight p.o. once a day for 30 days.

AQ-1000: WCF AqE $1000 \mathrm{mg} / \mathrm{kg}$ body weight p.o. once a day for 30 days. 


\section{Entries into open arm}

Further elucidated from the Figure 3, the mean entries into open arm increased significantly $(\mathrm{p}<0.001)$ for all the three doses of WCF AqE on days 15, 23 and 30 compared to control on those days. This increase was comparable with that of standard diazepam. Additionally, the dose response relationship was observed with WCF $\mathrm{AqE}$ for this parameter.

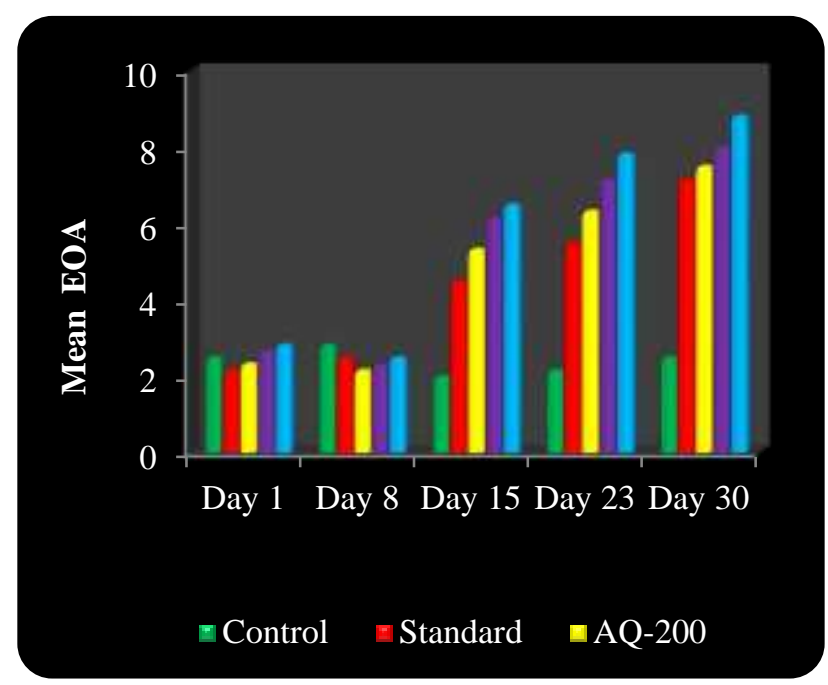

Figure 3: Effect of oral administration of WCF AqE on entries into open arm in the elevated plus maze test ( $n=6$ in each group).

WCF AqE: Withania coagulans fruits aqueous extract.

EOA: Entries into open arm.

Control: Vehicle (distilled water) $2 \mathrm{ml} / \mathrm{kg}$ p.o. once a day for 30 days.

Standard: Standard drug (diazepam) $5 \mathrm{mg} / \mathrm{kg}$ i.p. half an hour before test.

AQ-200: WCF AqE $200 \mathrm{mg} / \mathrm{kg}$ body weight p.o. once a day for 30 days.

AQ-500: WCF AqE $500 \mathrm{mg} / \mathrm{kg}$ body weight p.o. once a day for 30 days.

AQ-1000: WCF AqE $1000 \mathrm{mg} / \mathrm{kg}$ body weight p.o. once a day for 30 days.

\section{DISCUSSION}

In our study, as illustrated in the Table 1 and further clarified in (Figures 1, 2 and 3), on day 1 to day 8 there was no statistically significant difference in all the parameters like time spent in the open arm (open), time spent in the closed arm (close) and entries into open arm (EOA) for all the three doses of $200 \mathrm{mg} / \mathrm{kg}, 500 \mathrm{mg} / \mathrm{kg}$ and $1000 \mathrm{mg} / \mathrm{kg}$ of WCF AqE compared to control.
However, on day 15, day 23 and day 30 there were statistically highly significant increase $(p<0.001)$ in the parameters like open and EOA for the above doses of WCF AqE compared to control. In contrast, highly significant decrease $(p<0.001)$ was observed for the close. This increase or decrease was comparable to that of the standard diazepam. It is expected that the substance having antianxiety activity would significantly raise the time spent by mice in the open arm as well as entries into open arm compared to that of control. ${ }^{15,16}$ In contrast, time spent by mice in the closed arm would significantly decrease. Therefore, our results demonstrate the antianxiety activity for all three doses of WCF AqE comparable to diazepam in the elevated plus maze (EPM).

Our study is exceptional one as nobody has used the elevated plus maze to test the antianxiety activity of the aqueous extract of Withania coagulans fruits. However, this test was used to assess the antianxiety activity in Withania somnifera which closely resembles Withania coagulans. Bhattacharya et al in 2000 demonstrated that the glycowithanolides obtained from the roots of Withania somnifera had significant $(\mathrm{p}<0.05)$ anxiolytic activity at the doses of $20 \mathrm{mg} / \mathrm{kg}$ and $50 \mathrm{mg} / \mathrm{kg}$ orally. ${ }^{20}$ Both the time spent in open arm and the number of entries into the open arm were increased compared to control and same as that of standard lorazepam. ${ }^{20}$ On the other hand, time spent in the closed arm and number of entries into the closed arm were decreased. ${ }^{20}$

Similarly in another study, both the time spent in open arm and the number of entries into open arm were increased significantly $(\mathrm{p}<0.05)$ in middle cerebral artery occluded (MCAO) rodents treated with Withania somnifera root extract compared with MCAO rodents alone. $^{21}$ If we look toward plant species used in folk medicine such as Withania somnifera (Ashwagandha) which closely resembles Withania coagulans, it showed that withanolides work as antianxiety agent. ${ }^{22}$ Both Withania coagulans and Withania somnifera have abundant withanolides. Therefore, antianxiety action of Withania coagulans may be because of withanolides. It was found that $3 \beta$-hydroxy-2, 3-dihydrowithanolide $F$ is responsible for the antianxiety as well as CNS depressant action of the plant. ${ }^{23}$ It is the key challenge to understand the exact mechanism of action of withanolides for the antianxiety activity.

Maguire et al and Koonce et al confirmed that estrous cycle changes in female mice can considerably modify stage of anxiety during ovarian cycle..$^{24,25}$ Therefore, in our experiment we used only male mice to avoid impact of hormonal alterations over result. After each trial the equipment was cleaned with super hypochlorous water to prevent the bias based on olfactory cues. ${ }^{26}$ The elevated plus maze test has a robust predictive validity for screening anxiolytic drugs, therefore it has been used for drug discovery. ${ }^{27}$ 


\section{CONCLUSION}

To summarize, the results obtained in this study demonstrated potent antianxiety activity of Withania coagulans fruits aqueous extract in swiss albino mice by elevated plus maze. There is a need of much more work to be done on the receptor level to understand the exact mechanism of action of withanolides.

\section{Funding: No funding sources}

Conflict of interest: None declared

Ethical approval: The study was approved by the Institutional Ethics Committee

\section{REFERENCES}

1. Steimer T. The biology of fear and anxiety related behaviors. Dialogues Clin Neurosci. 2002;4(3):231.

2. Reddy VM, Chandrashekar CR. Prevalence of mental and behavioural disorders in India: a meta-analysis. Indian J Psychiatry. 1998;40(2):149.

3. Tiwari SC, Srivastava S. Geropsychiatric morbidity in rural uttar pradesh. Indian $\mathrm{J}$ Psychiatry. 1998;40(3):266-73.

4. World Health Organization (WHO). World Health Organization Manual of the international statistical classification of diseases, injuries and causes of death, ninth revision. Geneva, Switz; 1992.

5. Murthy. National mental health survey of India 20152016. Indian J Psychiatry. 2017;59(1):21.

6. Tylee A, Walters P. Onset of action of antidepressants. BMJ. 2007;334(7600):911-2.

7. Pandey I, Nama KS. Withania Coagulans (stocks) Dunal: A Rare Ethnomedicinal Plant of the Western Rajasthan Desert. IJPBR. 2015;2(2):34-40.

8. Pandey RP, Meena SL, Padhye PM, Singhadiya MK. A review of depleting plant resources, their present status and conservation in Rajasthan, India. In: Biological Forum. Satya Prakashan; 2012:213-230.

9. Budhiraja RD, Bala S, Garg KN. Pharmacological investigations on fruits of Withania coagulans, Dunal. Planta Med. 1977;32(2):154-7.

10. Qasim S, Zafar A, Saif MS, Ali Z, Nazar M, Waqas $M$, et al. Green synthesis of iron oxide nanorods using Withania Coagulans extract improved photocatalytic degradation and antimicrobial activity. J Photochem Photobiol B Biol. 2020;111784.

11. Lateef T, Qureshi SA. Centratherum anthelminticum and Withania coagulans improves lipid profile and oxidative stress in triton $\mathrm{X}-100$ induced hyperlipidemic rabbits. Group. 2020;1(11.36):1-22.

12. Ani AOA, Bazzaz AA. Glycated low-density lipoprotein in diabetic and non-diabetic patients. Asian J Pharm Clin Res. 2020;13(2):123-6.

13. Meeran SB, Subburaya U, Narasimhan G. In Silico and In Vitro Screening of Ethanolic Extract of Fruits of Withania Coagulans against Diabetes. Res J Pharm Technol. 2020;13(2):631-5.

14. Pellow S, Chopin P, File SE, Briley M. Validation of open: closed arm entries in an elevated plus-maze as a measure of anxiety in the rat. J Neurosci Methods. 1985;14(3):149-67.

15. Rodgers RJ, Dalvi A. Anxiety, defence and the elevated plus-maze. In: Neuroscience and Biobehavioral Reviews; 1997:801-810.

16. Korte SM, Boer DSF. A robust animal model of state anxiety: fear-potentiated behaviour in the elevated plus-maze. Eur J Pharmacol. 2003;463(1):163-75.

17. Guideline OO. 425: Acute oral toxicity up and down procedure. OECD Guidel Test Chem Organ Econ Coop Dev Paris; 2001.

18. Soxhlet F. Die gewichtsanalytische bestimmung des milchfettes. Polytech J. 1879;232:461-5.

19. Komada M, Takao K, Miyakawa T. Elevated plus maze for mice. Journal Vis Exp. 2008;(22):1088-8.

20. Bhattacharya1 SK, Bhattacharya A, Sairam K, Ghosaf S. Anxiolytic-antidepressant activity of Withania somnifera glycowithanolides: an experimental study. Phytomedicine. 2000;7(6):463-9.

21. Sood A, Kumar A, Dhawan DK, Sandhir R. Propensity of Withania somnifera to Attenuate Behavioural, Biochemical, and Histological Alterations in Experimental Model of Stroke. Cell Mol Neurobiol. 2015:1-16.

22. Singh N, Bhalla M, Jager DP, Gilca M. An overview on Ashwagandha: A Rasayana (Rejuvenator) of Ayurveda. African J Tradit Complement Altern Med. 2011;8(5):208-13.

23. Maurya R. Chemistry and pharmacology of Withania coagulans: an Ayurvedic remedy. J Pharm Pharmacol. 2010;62(2):153-60.

24. Maguire JL, Stell BM, Rafizadeh M, Mody I. Ovarian cycle-linked changes in $\mathrm{GABA}(\mathrm{A})$ receptors mediating tonic inhibition alter seizure susceptibility and anxiety. Nat Neurosci. 2005;8(6):797-804.

25. Koonce CJ, Walf AA, Frye CA. Type $15 \alpha$-reductase may be required for estrous cycle changes in affective behaviors of female mice. Behav Brain Res. 2012;226(2):376-80.

26. Liu A, Papale AE, Hengenius J, Patel K, Ermentrout B, Urban NN. Mouse navigation strategies for odor source localization. Front Neurosci. 2020;14.

27. Hogg S. A review of the validity and variability of the elevated plus-maze as an animal model of anxiety. Pharmacol Biochem Behav. 1996;54(1):2130 .

Cite this article as: Gosavi DD, Kamdi AS,

Kalambe SM, Bohra PN. The antianxiety activity of aqueous extract of Withania coagulans fruits in swiss albino mice by elevated plus maze. Int $\mathrm{J}$ Basic Clin Pharmacol 2020;9:1337-42. 